\title{
Frequency of Blood Culture Isolates and their Antibiogram in a Teaching hospital
}

\author{
Subha Shrestha, ${ }^{1}$ Ritu Amatya, ${ }^{1}$ Raj Kumari Shrestha, ${ }^{1}$ Rajiv Shrestha ${ }^{1}$ \\ 'Department of Microbiology, Nepal Medical College and Teaching Hospital, Jorpati, Kathmandu, Nepal.
}

\section{ABSTRACT}

Introduction: Bloodstream infections are associated with significant patient morbidity and mortality. Antimicrobial susceptibility patterns should guide the choice of empiric antimicrobial regimens for patients with bacteremia.

Methods: Blood sample received from the patient attending Nepal Medical College and Teaching Hospital from March, 2012 - August, 2012 were subjected to culture. Isolate identification and antimicrobial susceptibility testing was done by standard microbiological method.

Results: Out of the total 2,766 blood samples, 368 (13.3\%) showed bacterial growth. The percentage of neonatal septicemia was 368 (13.3\%). Staphylococcus aureus (28\%) was the most common isolates followed by Salmonella enterica Serotype Typhi (22\%), Coagulase negative Staphylococci $(9.5 \%)$, Salmonella enterica Serotype Paratyphi ((7.6\%) and Klebsiella pneumoniae $(7.6 \%) .26 .3 \%$ of the isolates of Staphylococcus aureus were oxacillin resistant. Most of the gram positive organisms were susceptible to amikacin and vancomycin and showed high level resistance to cefuroxime and cotrimoxazole. Out of 109 isolates of typhoid bacilli, $95.3 \%$ were resistant to nalidixic acid,79\% to ciprofloxacin and $60.5 \%$ to ofloxacin. More than $50 \%$ of the isolates of Klebsiella pneumoniae and Escherichia coli showed resistance to cephalosporins and cotrimoxazole. Acinetobacter sp. showed high resistance (more than $60 \%$ ) to ceftriaxone and ofloxacin. More than $20 \%$ of the isolates of Pseudomonas aeruginosa were resistant to ciprofloxacin and amikacin.

Conclusions: Ongoing surveillance for antimicrobial susceptibility remains essential, and will enhance efforts to identify resistance and attempt to limit its spread.

Keywords: antibiotic; bacteria; blood stream infections.

\section{INTRODUCTION}

Blood stream infections remain one of the most important causes of morbidity and mortality worldwide. ${ }^{1}$ Despite important progresses in treatment and prevention of infectious diseases, they are considered as leading causes of death and disability and worsening life quality especially for millions of people in developing countries.
Bacteremia has an increasing trend in some regions of the world. ${ }^{2}$ Bacteria isolated from bloodstream infections are numerous ${ }^{3-5}$ and their associated diseases need urgent and invasive management with antimicrobial drugs. Rational and correct use of these agents

Correspondence: Subha Shrestha, Department of Microbiology, Nepal Medical College and Teaching Hospital, Kathmandu, Nepal. Email: shresthasubha@hotmail.com, Phone: +977-9851005986. 
Shrestha et al. Frequency of Blood Culture Isolates and their Antibiogram in a Teaching Hospital

requires understanding of common pathogens and drug resistance pattern in the region. ${ }^{6}$ Nowadays, bacterial drug resistance is an important problem, and due to wide variations in bacterial drug resistance, results of studies and reports vary from one region to another and in different periods of time. ${ }^{3,6,7}$ The surveillance of blood stream pathogens in a hospital is important in monitoring the spectrum of microorganisms that invade the blood stream and the types of organisms associated with a particular clinical discipline. Such data are often used to determine empiric antibiotic therapy and also to alert the clinicians to emerging pathogens that may pose a threat to the community. ${ }^{8}$

As there are limited published data on common etiological agents of blood culture isolates and their antibiogram in our set up, we attempt to determine the prevalence of bacteria causing bloodstream infections and their drug resistance in microbiology laboratory of Nepal Medical College and Teaching Hospital, Kathmandu.

\section{METHODS}

The study included all blood samples for culture obtained from the patients who presented to the Nepal Medical College and Teaching Hospital with a history of fever of variable duration from March $1^{\text {st }}, 2013$ to August $31^{\text {st }}$ 2013. Blood samples were cultured in Brain Heart infusion (BHI) broth which supports the growth of all common pathogens causing bacteremia/septicemia. Collection of blood, aerobic incubation, and subculture(s) onto blood agar, MacConkey agar and identification of the organisms were done as per the standard microbiological method. ${ }^{9}$ The antimicrobial susceptibility testing was done by Kirby-Bauer disc diffusion technique that is recommended by Clinical Laboratory Standards Institute (CLSI) recommendations. ${ }^{10}$

\section{RESULTS}

Out of the total 2,766 blood samples received in the microbiology laboratory for the culture and sensitivity, $368(13.3 \%)$ showed culture positive. Out of these, $238(64.7 \%)$ were from male patients and 130 $(35.3 \%)$ from female. The percentage of neonatal sepsis is $13.3 \%$. Staphylococcus aureus (14) was the commonest organism causing neonatal septicemia followed by Acinetobacterspp (12). The overall incidence of gram positive and gram negative organisms were $44.8 \%$ and $55.2 \%$ respectively. Staphylococcus aureus, $103(28 \%)$ remained the predominant isolate, followed by Salmonella enterica Serotype Typhi, 81 (22\%), Coagulase negative Staphylococci, 35 (9.5\%), Salmonella enterica Serotype Paratyphi, 28 (7.6\%) and Klebsiellapneumoniae, 28 (7.6\%)(Table 1).

\begin{tabular}{|ll|}
\hline $\begin{array}{l}\text { Table 1. Frequency of blood culture isolates } \\
\text { (n= 368). }\end{array}$ \\
\hline Organism \\
GRAM POSITIVE BACTERIA \\
Staphylococcus aureus \\
Coagulase negative Staphylococci & $103(28)$ \\
Enterococci sp. & $35(9.5)$ \\
Streptococcus sp. & $18(5)$ \\
Streptococcus pneumoniae & $7(1.9)$ \\
GRAM NEGATIVE BACTERIA & $2(0.5)$ \\
Salmonella Typhi & \\
Salmonella Paratyphi & $81(22)$ \\
Klebsiella pneumoniae & $28(7.6)$ \\
Acinetobacterspp & $28(7.6)$ \\
Escherichia coli & $26(7.1)$ \\
Pseudomonas aeruginosa & $18(4.9)$ \\
Proteus sp. & $8(2.1)$ \\
Enterobacter sp. & $5(1.3)$ \\
Citrobacter sp & $5(1.3)$ \\
\hline
\end{tabular}

Staphylococcus aureus showed $35.9 \%$ of resistance to azithromycin, $30 \%$ to ceftazidime, $28.1 \%$ to Cotrimoxazole. Oxacillin Resistant Staphylococcus aureus were $26.3 \%$. All the isolates of Staphylococcus aureus were susceptible to Vancomycin and Amikacin. CoNS showed high percentage of resistance to Azithromycin (62.5\%) and ceftriaxone (33.3\%). All the isolates of Enterococci sp. were susceptible to Amikacin, azithromycin and Vancomycin. Enterococci sp. showed $40 \%$ resistance to Gentamicin (not shown in the table) and $33 \%$ to cotrimoxazole. Of the total 109 isolates of Salmonella Typhi and Salmonella Paratyphi which cause enteric fever, $95.3 \%$ were resistant to Nalidixic acid ,79\% to Ciprofloxacin and $60.5 \%$ to Ofloxacin. Resistance to other antibiotics like Cephalosporins, Cotrimoxazole, Amikacin and Chloramphenicol were negligible. More than $50 \%$ of the isolates of Klebsiella pneumoniae and Escherichia coli showed resistance to Cephalosporins and Cotrimoxazole. Acinetobacter sp. showed high resistance (more than 60\%) to Ceftriaxone, Ciprofloxacin and Ofloxacin. More than $20 \%$ of the isolates of Pseudomonas aeruginosa were resistant to Ciprofloxacin andAmikacin. Tobramycin and piperacillin-tazobactam were found to be more satisfactory among Pseudomonas aeruginosa (Table 2). No fungi was isolated in the present study. 
Table 2. Percentage of antimicrobial resistance patterns of common blood culture isolates .

\begin{tabular}{|c|c|c|c|c|c|c|c|c|}
\hline 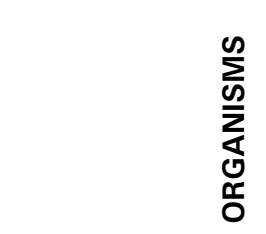 & 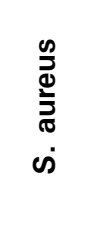 & $\begin{array}{l}\text { n } \\
\text { Z } \\
0\end{array}$ & 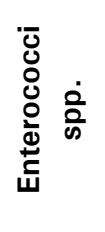 & 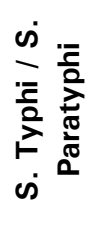 & 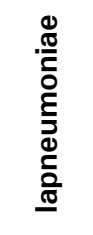 & $\begin{array}{l}\overline{\bar{o}} \\
\text { ن }\end{array}$ & 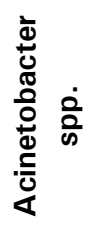 & 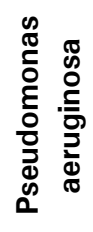 \\
\hline Amikacin & 0 & 0 & 0 & 3 & 9 & 40 & 6.2 & 21.6 \\
\hline Azithromycin & 35.9 & 26.5 & 0 & - & - & - & 16.7 & - \\
\hline Oxacillin & 26.3 & 2 & - & - & - & - & - & - \\
\hline Vancomycin & 0 & 0 & 0 & - & - & - & - & - \\
\hline Ciprofloxacin & 15.1 & 6.7 & 16.7 & 79 & 25 & 70 & 66.7 & 23 \\
\hline Ofloxacin & 14.7 & 16.7 & 11.1 & 60.5 & 17 & 57 & 64.7 & 16.2 \\
\hline Cotrimoxazole & 28.6 & 20 & 33.3 & 6.4 & 71.4 & 55 & 11.1 & 43 \\
\hline Cefotaxime & 19.5 & 20 & - & 3.6 & 66.7 & 60 & 16.7 & - \\
\hline Ceftriaxone & 19 & 33.1 & - & 5.5 & 66 & 54 & 60.9 & - \\
\hline Cefuroxime & 30 & - & - & 7.3 & 70.5 & 54.4 & 37.5 & - \\
\hline Chloramphenicol & 3.8 & 0 & 16.6 & 3.1 & 6.3 & 33.3 & 30 & 35.2 \\
\hline Nalidixic acid & - & - & - & 95.3 & - & - & - & - \\
\hline Tobramycin & - & - & - & - & - & - & - & 18 \\
\hline $\begin{array}{l}\text { Piperacillin } \\
\text { Tazobactam }\end{array}$ & - & - & - & - & - & - & - & 14.2 \\
\hline
\end{tabular}

\section{DISCUSSION}

Patients with bacteremia have remained a challenge to treat. Knowledge of the hospital epidemiology and antimicrobial resistance pattern of blood isolates helps physicians to effectively manage bloodstream infections. ${ }^{11}$ In the present study, $13.3 \%$ of the total sample comprised the culture positivity, which is very close to the finding of study done in Kuala Lumpurl. ${ }^{8}$ However, different studies have reported variable results $(10.23 \%-45.9 \%)^{9-12}$ which can be due to reasons like different methods of blood culture, administration of prior antibiotics, and infection with anaerobes or effective control in spread of nosocomial infection.

In the present study, gram negative bacilli (55.2\%) represents the majority of the isolates causing blood steam infection. However, Staphylococcus aureus (28\%) was the most frequent organism isolated. This can be comparable to the study where $60 \%$ of the infections were by gram negative bacilli and Staphylococcus aureus $(21.3 \%)$ was the most frequent pathogen. CoNS had been reported as the most common organism from blood culture isolates from different studies. ${ }^{12-14}$ The present study isolated $9.5 \%$ of the CoNS. The clinical significance of CoNS when isolated from blood cultures should always be evaluated. Some studies have reported that upto $85 \%$ of CoNS represent contamination rather than true bacteremia. ${ }^{15,16}$ However, in recent years, CoNS have become an important nosocomial pathogen partly because of the increasing use of medical devices such as long term indwelling catheters, vascular grafts, and prosthetic heart valves and joints. ${ }^{17,18}$

Enteric fever is one of the common public health problems in Nepal. The present study reported high prevalence of Salmonella Typhi $(22 \%)$ and Salmonella Paratyphi $(7.6 \%)$. Findings of present study indicated the endemicity of enteric fever in the peri-urban area of Kathmandu Valley. The overall growth positive rate for Salmonella spp was relatively low $(5.4 \%)$ in a previous study done in the same institution and in other studies(5.1\%, 6.9\%). ${ }^{19-21}$ 
Amongst the Enterobacteriaceae, Klebsiella pneumoniae $(7.6 \%)$ were the most frequent isolates followed by $4.9 \%$ Escherichia coli, $1.3 \%$ each spp of Proteus and Enterobacter sp. and $1.2 \%$ Citrobacter sp. High percentage of isolation of Escherichia coli $(21.1 \%)$ and Klebsiella pneumoniae $(8.3 \%)$ are reported in study done by Arora et al. ${ }^{22}$ The isolation of nonlactose fermenters like Acinetobacter sp. (7.1\%) and Pseudomonas aeruginosa(1.3\%) revealed in the current study, though low, is of concern. Both of these bacteria are associated with a high degree of resistance to antibiotics. High occurrence of these bacteria in blood stream infections is reported by study done in South India. ${ }^{22}$

In the present study, all staphylococcal isolates and Enterococci spp were susceptible to vancomycin and amikacin. Oxacillin resistance is reported in $26.3 \%$ of the $\mathrm{S}$ aureus which is comparable to the study done by Rina et al. ${ }^{8}$ However, James et al, reported high percentage of Oxacillin resistant Staphylococci $(49.3 \%) .{ }^{23}$ Greater than $30 \%$ of Enterococci sp. were resistant to Cotrimoxazole.

The current study shows high resistance of Salmonella Typhi and Salmonella Paratyphi to Nalidixic acid(95.3\%), the prototype of Quinolone, and the fluoroquinolones , Ciprofloxacin (79\%) and Ofloxacin (60.5\%) which is comparable to the study done by Dhiraj et al. ${ }^{24}$ In previous studies, Ciprofloxacin was reported to be most effective. ${ }^{25-27}$ These observations may have important clinical significance, given that with the emergence of multidrug resistant Salmonella Typhi, quinolone particularly Fluoroquinolones has been widely used and recommended as an alternative drug for typhoid fever, and their resistance may be due to irrational use without prescription and misuse of antibiotics even for milder cases is common in Nepal. More than $90 \%$ of the typhoid bacilli were susceptible to Aminoglycosides, Cephalosporins and Cotrimoxazolein the present study.

Among the gram negative bacteria in the current study, Klebsiella pneumoniae, Escherichia coli, and Acinetobacter sp. were highly resistant to cephalosporins in the present study. A study done in Pakistan had showed similar rate of resistance to cephalosporins by gram negative bacilli. ${ }^{12}$ More than $85 \%$ of the isolates of Pseudomonas aeruginosa were susceptible to tobramycin and piperacillin/tazobacatam. However, Babak et al, had reported high level of resistance of Pseudomonas aeruginosa to almost all the antibiotics tested. ${ }^{13}$ In the present report, none of the antimicrobial agents tested were sufficiently effective against Escherichia coli isolates in vitro. Therefore, physicians and hospital formulary groups need to search for other effective antimicrobial agents against infections caused by these drug resistant bacteria.

\section{CONCLUSION}

Data derived from this study shows that, with a few exceptions (vancomycin susceptible to gram positive cocci and cephalosporin susceptible to typhoid bacilli), resistance to most antimicrobial agents for a number of species implicated in bacteremia has reached worrisome levels. High resistance to recommended drugs like cephalosporins, aminoglycosides and fluroroqinolones are of major concern and aware the clinicians and the health care workers to seek for alternative antimicrobial agents. Our data underscore the need for periodic survey of etiological agents and their resistance surveillance reports which can provide valuable insight into resistance trends to assist in guidance in the appropriate choice of empiric therapy.

\section{REFERENCES}

1. Bailey and Scott's Diagnostic microbiology: A textbook for isolation and identification of pathogenic microorganisms. In 11th edition Edited by Forbes BA, Sahm DF, Weissfeld AS. St. Louis: The Mosby Company; 2002:378-422.

2. Braunwald F, et al. Infectious diseases. In: Harrison TR, et al. Harrison's Principles of Internal Medicine.14th ed. New York; McGrow-Hill 1998;P:749-783, 2419-20.

3. Reacher MH, Shah A,LivermoreDM,Wale MC , Graham C, Johnson AP, Heine H,Monnickendam MA, Barker KF,James
D.Bacteraemia and antibiotic resistance of its pathogens reported in England and Wales between 1990 and 1998: Trend Analysis. BMJ. 2000;320(7229):213-6.

4. Huang SS, Labus BJ, Samuel MC, Wan DT, Reingold AL. Antibiotic resistance patterns of bacterial isolates from blood in San Francisco County, California, 1996-1999. Emerg Infect Dis. 2002;8(2):195-201.

5. Friedland IR, McCracken GH. Management of infections caused by antibiotic-resistant Streptococcus Pneumoniae. N Engl J Med. 1994;331(6):377-82. 
6. Cohen ML. Epidemiological factors influencing the emergence of antimicrobial resistance. Ciba Found Symp. 1997;207:223-231.

7. Sobhani A, Shodjai H, Khalkhali-Rad Sh. Survey on relative frequency Staphylococus resistance in samples refferred to (Razi hospital lab, Rasht, 1998). Rasht, Guilan University of Medical Sciences 1998.

8. Karunakaran R, Raja NS, Ng P K, Navaratnam P. Etiology of blood culture isolates among patients in multidisciplinary teaching hospital in Kuala Lumpur. J MicrobiolImmunol Infect. 2007;40:432-7.

9. Collee JG, Miles RS, Watt B. Tests for the identification of bacteria. In: Collee JG, Fraser AG, Marmion BP, Simmons A, editors. Mackie and McCartney Practical medical microbiology. 14th ed. London: Livingstone, 1996:131-49.

10. Clinical and Laboratory Standards Institute. Performance 12 Standards for Antimicrobial Susceptibility Test. 9th ed. ApprovedStandard. Wayne, PA: Clinical and Laboratory Standard Institute; 2006. (CLSI document no. M2-A9).

11. Arpi M, Victor MA, Moller JK, Jonsson V, Hansen MM, Peterslund NA, Bruun B. Changing etiology of bacteremia in patients with hematological malignancies in Denmark. Scand J Infect Dis. 1994;26:157-62.

12. Meremikwu MM, Nwachukwu CE, Asuquo AE, Okebe JU, Utsalo SJ. Bacterial isolates from blood cultures of children with suspected septicaemia in Calabar, Nigeria. BMC Infectious Diseases. 2005;5:110.

13. Pourakbari B, Sadr A, Ashtiani MTH, MamishiS, Dehghani M, Mahmoudi S, et al. Five-year evaluation of the antimicrobial susceptibility patterns of bacteria causing bloodstream infections in Iran. J Infect Dev Ctries. 2012;6(2):120-5.

14. Dagnew M, Yismaw G, Gizachew M, Gadisa A, Abebe $\mathrm{T}$, Tadesse et al. Bacterial profile and antimicrobial susceptibility pattern in septicemia suspected patients attending Gondar University Hospital, Northwest Ethiopia. Dagnew et al. BMC Research Notes. 2013;6:283.

15. Towns ML, Quartey SM, Weinstein MB, Reimer LG, Reller LB. The clinical significance of positive blood cultures: a prospective, multicenter evaluation. In: Abstracts of the $93^{\text {rd }}$ General Meeting of the American Society for Microbiology, C-232. Washington, DC: American Society for Microbiology;1993.

16. Weinstein MP, Towns ML, Quartey SM, Mirrett S, Reimer LG, Parmigiani G, et al. The clinical significance of positive blood cultures in the 1990s: a prospective comprehensive evaluation of the microbiology, epidemiology, and outcome of bacteremia and fungemia in adults. Clin Infect Dis. 1997;24:584-602.
17. Reimer LG, Wilson ML, Weinstein MP. Update on detection of bacteremia and fungemia. ClinMicrobiol Rev. 1997;10:444-65.

18. Weinstein MP, Mirrett S, Van Pelt L, McKinnon M, Zimmer $\mathrm{BL}, \mathrm{Kloos} \mathrm{W}$, et al. Clinical importance of identifying coagulase-negative staphylococci isolated from blood cultures: evaluation of MicroScan Rapid and dried overnight Grampositive panels versus a conventional reference method. J ClinMicrobiol. 1998;36:2089-92.

19. Pokharel P, Rai SK, Karki G, Katuwal A, Vitrakoti R, Shrestha SK. Study of enteric fever and antibiogram of Salmonella isolates at a Teaching Hospital in Kathmandu Valley. Nepal Med CollJ. 2009;11(3):176-8.

20. Sharma NP, Peacock SJ, Phumratanaprapin W, Day N, White N, Pukrittayakamee S. A hospital-based study of bloodstream infections in febrile patients in Dhulikhel Hospital, Kathmandu University Teaching Hospital, Nepal. Southeast Asian J Trop Med Public Health. 2006;37:351-6.

21. Khanal B, Sharma SK, Bhattacharya SK, Bhattarai NR, Deb M, Kanungo R. Antimicrobial susceptibility patterns of Salmonella entericaSerotype typhiin eastern Nepal. J HealthPopulNutr. 2007;25:82-7.

22. Arora U, Devi P. Bacterial profile of blood stream infections and antibiotic resistance pattern of isolates. JK Science. 2007;9:186-90.

23. Karlowsky JA, Jones ME, Draghi DC, Thornsberry C, Sahm DF and Volturo GA. Prevalence and antimicrobial susceptibilities of bacteria isolated from blood cultures of hospitalized patients in the United States in 2002. Annals of Clinical Microbiology and Antimicrobials. 2004;3:7.

24. Acharya D, Bhaata DR, Malla S, Dumre SP, Adhikari N, kandel Bp. Salmonella entericaserovar Paratyphi A: an emerging cause of febrile illness in Nepal. Nepal Med Coll J. 2011;13(2):69-73.

25. Murdoch DR, Woods CW, Mark DZ et al. The etiology of febrile illness in Adults presenting to Patan Hospital in Kathmandu, Nepal. Amer J Trop MedHyg.2004;70:670-5.

26. Gupta V, Kaur J, Chander J. An increase in enteric fever cases due to Salmonella paratyphiA in and around Chandigarh. Indian J Med Res. 2009;129:95-8.

27. Bhatia JK, Mathur AD, Arora MM. Reemergence of chloramphenicol sensitivity in enteric Fever. Med J ArmedForces India. 2007;63:212-4. 